\title{
Using geoinformation tools for redistricting: Slovenian experiences
}

\author{
Boštjan RogeljA*, Marko Krevs ${ }^{\mathrm{A}}$ \\ Received: February 07, 2021 | Revised: May 09, 2021 | Accepted: May 21, 2021 \\ doi: 10.5937/gp25-30752
}

\begin{abstract}
Electoral districts are an important component of the electoral system, as they have a significant impact on election results. Due to the uneven spatial distribution of electoral support political parties receive, district magnitude and the geography of electoral districts can have a decisive influence on the electoral viability of individual parties and candidates. Districting and redistricting are not a simple bureaucratic process but a politically very sensitive process with outcomes that can have far-reaching political consequences.
\end{abstract}

Geoinformation tools can have a very important role in electoral district planning. In this article we aim to present the key advantages and disadvantages of their use. The presented results are derived from practical experience gained over the course of developing a new system of electoral districts in Slovenia.

Keywords: electoral geography; electoral districts; redistricting; geoinformatics; spatial decision support; Slovenia

\section{Introduction}

Electoral districts are one of the key elements of the electoral system. Together with the electoral formula, the structure of ballot papers and the electoral threshold, they determine how the votes are translated into parliamentary seats (Gallagher \& Mitchell, 2005; Grad, 2004; Krašovec, 2007). District magnitude - the number of seats awarded within an electoral district - has a particularly significant effect on election results. In general, delimiting a territory into a larger number of smaller districts increases the impact of each vote on the election outcome. With reductions in magnitude, the importance of the geography and spatial dimensions of electoral districts increases. Due to the uneven spatial distribution of electoral support for political parties, the geography of electoral districts can have a decisive influence on the electoral prospects of individual parties and candidates. Districting and redistrict- ing of electoral districts are therefore a very complex and often highly politicized process in which various actors want to assert their narrow political interests.

We roughly distinguish two ways to delimit electoral districts (ACE Project, 2020). In the first case, spatial dimensions of the electoral district are determined first, followed by a determination of its magnitude. Spatial dimensions are usually determined on the basis of existing administrative-territorial divisions within a territory, and the magnitude on the basis of the number of inhabitants or voters using simple mathematical formulas. This way of forming electoral districts is relatively simple and less susceptible to manipulation.

In the second case, the magnitude of districts is determined first, followed by a determination of their spatial dimensions. Spatial dimensions are deter-

\footnotetext{
A University of Ljubljana, Faculty of Arts, Department of Gerography, Slovenia, bostjan.rogelj@ff.uni-lj.si; marko.krevs@ff.uni-lj.si

* Corresponding author: Boštjan Rogelj; e-mail: bostjan.rogelj@ff.uni-lj.si
} 
mined on the basis of various, often conflicting criteria. Due to the requirements to take into account different criteria and their arbitrary nature, such an approach of drawing districts is very complex and often subject to various manipulations. Drawing of electoral districts to the advantage of a particular political party or group is referred to as gerrymandering (Morrill, 1981).

Very early on electoral district planners realized the usefulness of geoinformation tools. These tools allow them to incorporate into the design process a broad spectrum of information, that can be used to develop a larger number of proposals in a relatively short timeframe. With the help of spatial and statistical analyses, they can more effectively and more quickly assess the suitability of different proposals. However, new tools increase the possibility of manipulation. Thanks to the tools it is now easier, quicker, and cheaper to design proposals that meet the specif- ic political interests of individual actors (Eagles et al., 2000; 1999).

In this article we aim to present the key advantages and disadvantages of using geoinformation tools for districting and redistricting electoral districts. Both authors were members of an expert group that prepared a proposal for a new system of electoral districts in Slovenia. The presented results stem from practical experience gained while working in the expert group in the period from March 2019 to March 2020.

The article consists of four parts. The introductory part is followed by a brief presentation of some theoretical aspects of the use of geoinformation tools in districting and redistricting. The third part presents and critically evaluates the use of geoinformation tools in the reorganisation of the system of electoral districts in Slovenia. In the conclusion, an assessment of the usefulness of geoinformation tools in the process of districting and redistricting is provided.

\section{Electoral district plans and geoinformation tools}

Designing electoral district plans is a very complex and labour-intensive process that requires the processing of a myriad of spatial and statistical data. As manual data processing is time consuming, electoral district planners started using computers in their work very early on. The first examples of the use of geoinformation tools can be traced back to the 1960s (Nagel, 1965; Weaver \& Hess, 1963), however, for a long time they were used in a limited way. This reflects that the tools were inaccessible, had limited capacities and were complicated to use, and above all, were extremely costly. The situation began to change in the 1990s, when the first commercial GIS tools appeared on the market (Altman \& McDonald, 2019). These were more powerful and user-friendly. An important innovation was the development of graphical user interfaces, which enabled the visualization of spatial and statistical data. The next turning point in their development was the expansion of broadband internet, cloud services and opensource programs and applications. In the last decade, these changes have significantly reduced the cost and increased the availability of geoinformation tools (Altman \& McDonald, 2019).

We can identify three roughly defined areas of application for geoinformation tools in electoral district planning processes:

- support for human planners,

- evaluation of district plans,

- automated districting and redistricting.

Geoinformation tools are of great help to electoral district planners at all stages of their work. They play an important role already in the preparation and processing of data, as they enable linking of statistical and spatial data. With the aid of the tools, planners can quickly and easily define the spatial dimensions of an electoral district, obtain basic statistical information about it (number of inhabitants, area, perimeter, etc.) and check whether it meets the established criteria. In the final phase, they enable the production of accurate cartographic representations of proposed solutions. Their use has greatly facilitated, accelerated and reduced the cost of districting and redistricting, and at the same time has reduced the number of various errors. The use of geoinformation tools was initially very limited, but with the advent of free opensource web applications, the whole process has been democratized. The drafting of electoral district plans is no longer restricted to a narrow circle of experts but is open to different actors (Altman \& McDonald, 2019; Crampton, 2013). Today, an individual with basic computer skills and simple hardware can prepare a plan of electoral districts drawing on publicly available spatial and statistical data and with the help of open-source online applications.

Evaluating the suitability of proposed plans is another area of application for geoinformation tools. With their help, it is possible to quickly and easily check the extent to which an individual proposal meets set criteria. Furthermore, they can be used to identify different forms of manipulation more easily and quickly. This is particularly important when decision-makers and stakeholders need to consider and evaluate a large number of proposals. In addi- 
tion to their many advantages, geoinformation tools also bring certain risks and pitfalls. Above all they increase the possibility of manipulation. The application of geoinformation tools in electorate planning has increased the incidence, efficiency, and sophistication of gerrymandering. Thanks to the tools, it is possible to design plans that satisfy the narrow interests of individual political actors much faster and more efficiently (Altman et al., 2005). Through spatial analysis of data on the socio-economic and demographic characteristics of the population and their electoral preferences, political actors can design electoral district maps that meet the prescribed legal criteria, while at the same time maximizing their own political interests. This problem was particularly acute in the past, when geoinformation tools were only accessible to a relatively narrow circle of users due to their high cost. The proliferation of free open-source web applications has not eliminated the gerrymandering problem, but has empowered civil society actors engaged in and monitoring (re)districting (Altman \& McDonald, 2019; Crampton, 2013).

The third area of application of geoinformation tools is automated districting and redistricting. With the development of geoinformation tools, ideas have emerged to use them to automate electoral district planning (Altman et al., 2005). The idea is based on the assumption that the planning of electoral districts is fundamentally a mathematical problem (i.e. a partitioning problem) or a combinatorial optimization problem, which can be solved most quickly and efficiently with the help of computers. Proponents of automation argue that computers and geoinformation tools can be used to design optimal, transparent, and politically neutral electoral district plans (Browdy, 1990; Gudgin \& Taylor, 1979; Hess et al., 1965; Vickrey, 1961; Weaver \& Hess, 1963).

In practice, complete automation of districting and redistricting has proven to be much more difficult to implement than its proponents claim. The division of territory into electoral districts is a very complex mathematical problem that cannot be solved even with the help of state-of-the-art computers (Altman, 1998; 1997). What is more, automation has been shown not to provide politically neutral solutions. Altman (1997) notes that neutrality depends on three factors: 1. the process chosen; 2 . goals of the system; 3 . the outcomes from efforts to achieve these goals within specific demographic and political circumstances. Today, there is a growing belief that given a lack of general consensus on what constitute objectively neutral goals, no automation is neutral.

\section{Use of geoinformation tools in electoral redistricting in Slovenia}

The electoral system used in the elections of deputies to the National Assembly of the Republic of Slovenia is characterized by a unique electoral districts model. The territory of the country is divided into eight electoral districts and 88 constituencies for election purposes. Within each electoral district 11 seats are awarded, and accordingly, each district is subdivided into 11 constituencies. The National Assembly Election Act stipulates that electoral districts and constituencies be formed in accordance with the principle that each deputy is elected to represent approximately the same number of inhabitants. The law also stipulates that the formation of electoral districts and constituencies must take into account the geographical integrity along with common cultural and other characteristics.

In practice, these provisions are very difficult to harmonize. Significant regional fragmentation and uneven population density in the country make it impossible to create geographically consistent and equally populous spatial units. In the past, the first provision was the principal consideration in designing electoral districts (electoral districts have the same number of inhabitants though are not geographically consistent), while the second provision was taken into account when designing constituencies (the map of constituencies largely reflects the 1992 administrative-territorial division of the state into municipalities).

The system of electoral districts and constituencies has not undergone major changes since its introduction in 1992, this is despite the fact that there have since been significant changes in the spatial distribution of the population and the administrative system of the state. In 2017, a procedure was initiated at the Constitutional Court to review the constitutionality of the current system of constituencies. The Constitutional Court ruled that because of the large differences in the size of constituencies (in 2019 the most populous constituency had 31,694 voters, whereas the smallest had 7,945) and inconsistencies between constituency borders and the new administrative division of the state into municipalities, the existing system of constituencies is unconstitutional. The Constitutional Court therefore ordered the National Assembly to correct the unconstitutional situation within two years.

In April 2019, the Ministry of Public Administration established a working group tasked with preparing a proposal to amend the system of constituencies. The working group which was led by the authors of 
this article prepared three proposals for a new system of constituencies. The use of geoinformation tools in the work of the working group is presented and critically evaluated below. Above all, we want to present where and how we used them as well as what problems we encountered.

The working group used geoinformation tools in all three previously discussed areas of application. Most of the work was completed using the desktop and online versions of ArcGIS. In the first phase, we used these tools to prepare the relevant spatial data consisting of geoinformation layers on census tracks, settlements, municipalities, administrative and statistical regions provided by the Surveying and Mapping Authority of Slovenia (Register of spatial units, 2019). Data on voters (these data are not publicly available) by house numbers were extracted from the National Population Register run by Ministry of the Interior (Number of voters..., 2019) and aggregated at different spatial levels (from census tracts as the smallest aggregation units, local communities and urban and village districts, settlements, to municipalities as the largest aggregation units). Aggregated data on the num- ber of voters formed the basis for planning individual constituencies, as we wanted to create constituencies that were as similar in population as possible. Various spatial data layers (topographic maps in various scales, road maps, and detailed city plans) played an important role as we relied on them to create constituencies that were as geographically consistent as possible. Geoinformation tools were also used to check for possible inconsistencies in borders between neighboring constituencies or between the sums of voters in individual constituencies and the target number of voters in an electoral district. They were used to quickly and easily check how well the borders of proposed constituencies conformed with important natural geographical divides in regions and to existing administrative-territorial divisions of the state. In the final phase, they were used to prepare cartographic representations (Figure 1) and present the basic characteristics (number of voters, list of spatial units) of the proposed constituencies. We also used them to compare proposals and existing arrangements.

Evaluation of the suitability of the proposed redistricting was another area where geoinformation tools

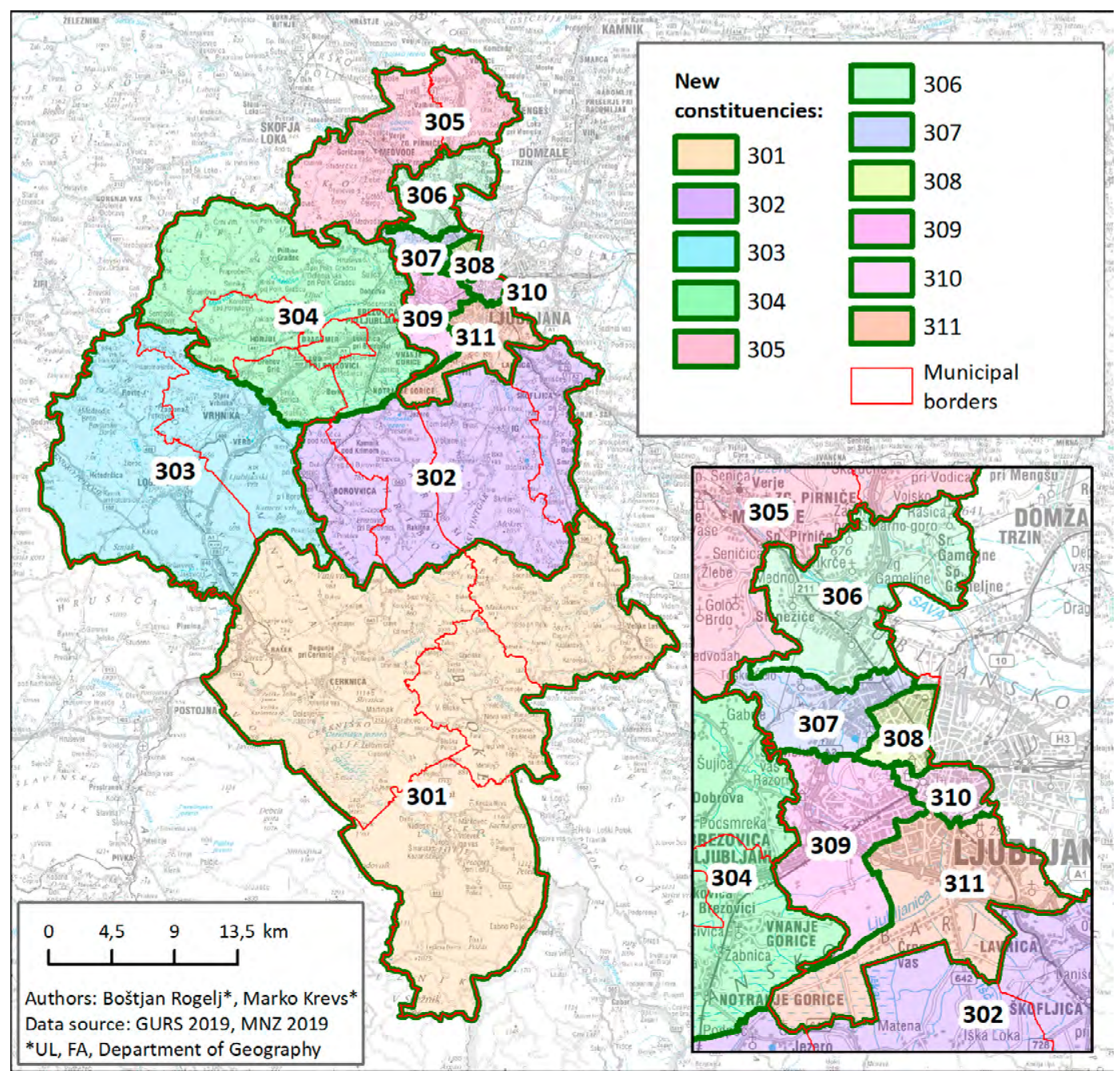

Figure 1. Map of the proposed system of constituencies in one of the electoral districts 

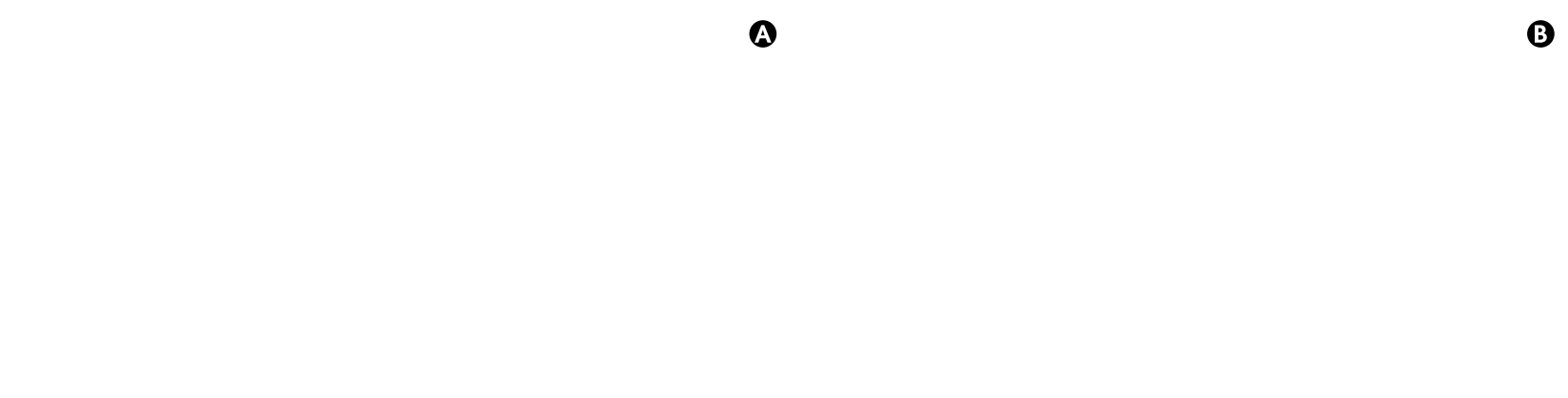

Figure 2. Web application for drafting proposals for new constituencies, that was made available to political parties in action A) visually comparing different proposed systems of constituencies and B) preparing to export a new proposal of a constituency, based on the materials and application carried out by external partners in the project

(Jelen et al., 2019; Veršič \& Jelen, 2019) [click on figure to enlarge]

were employed. Redistricting is a politically very sensitive issue, as it can have a significant impact on the electoral prospects of individual candidates (Webster, 2004). To guard against accusations of a lack of transparency and bias in the proposed solutions, the working group, in collaboration with external partners, developed a web application (Figure 2; Jelen et al., 2019) using ArcGIS Online, which provided parliamentary party representatives with a detailed overview of the proposed solutions, while it also enabled them to prepare alternative proposals.

Automated districting was the third area where the working group used geoinformation tools. The working group got external partners to develop a test version of an application for automated constituency redistricting. The first results of the application highlighted some problems that were impossible to solve within the set time frame and with limited resources (more on this below). While the idea of automation has not been fully realized, preliminary attempts have yielded some encouraging results.

The above highlights the versatile applicability of geoinformation tools using the example of redistricting of constituencies in Slovenia. In this regard, it is worth noting the irreplaceable assistance these tools provide to human planners. Without exaggeration, we can say that without their help it would have been impossible to prepare three proposals for a new constituency system in such a short time (the deadline for submitting the first proposal was two months, the same time frame applied for the preparation of amended proposals) (Rogelj et al., 2019a, 2019b). Their role in checking for and detecting possible errors is also very important. Thanks to the tools, we were able to quickly and easily check whether the proposed solution met the set criteria (in terms of the number of voters, harmonization of borders with the borders of different spatial units, etc.) and whether we made a mistake in determining the boundaries. The biggest shortcoming turned out to be the vague definition of a constituency (using terms such as geographical or cultural homogeneity used as defining principles, missing criteria for equal size of the constituencies) which meant that no relevant demographic, economic or data related to cultural characteristics were used. As a result, not all the possibilities offered by modern geoinformation tools were taken advantage of. For example, in planning constituencies, we could not take into account demographic trends (net changes in the number of voters by different territorial units would be especially helpful) and some aspects of functional connections present between settlements/municipalities (e.g. the number of daily migrants, access to different services).

Use of the web application for providing detailed insights into proposed solutions and for preparing alternative proposals turned out to be a very interesting experience. Despite training potential users of the application and urging parliamentary parties to make use of it to submit their proposals, uptake was very limited (Krevs et al., 2020). There were two reasons for this. The first was the great complexity of the task. Deputies had many ideas on how to transform individual constituencies, but when it came to finding a comprehensive solution at the level of the electoral district or the state, their proposals often proved to be deficient and inappropriate. In conversations, many admitted that the task - despite its apparent simplicity - was more difficult to accomplish than they had envisaged. The design of the application is another reason for the modest response. Given the short time frame available to us for its development, the application was not the most user-friendly. To use key functions users required some practice and a certain amount of geographical and computer skills and knowledge. While most users unfamiliar with geoinformation tools gave up very quickly, a few political parties took advantage of the application in coming up with some of their own proposals. The members of the working group and the developers of the application believe that with different (longer) time frames and sufficient financial support, it would be possible to create a more user- 
friendly application that would be useful both for representatives of political parties and the general public. This would significantly increase the transparency of the whole process.

Most of the open questions that remain concern the use of geoinformation tools for automated districting. We mentioned that the idea of automation has not been fully realized. The first attempts yielded some encouraging results, while at the same time highlighted some key issues. Among them, it is worth mentioning the selection of appropriate criteria and determination of the hierarchy of selected criteria or measures.

We previously noted that the law very loosely sets out the criteria for districting constituencies. Constituencies are supposed to be the same size (by population) and geographically consistent, but nowhere is it specified what size deviations are allowed and what criteria should be taken into account when assessing the geographical consistency of constituencies. Defining more precise criteria was therefore the first task of the working group. After careful consideration, we identified seven basic criteria (Table 1). In practice, it turned out that the criteria were too ill-defined in certain situations, and they were not able to be used to come up with suitable solutions. In such cases, we used additional criteria such as transport connectivity, degree of urbanization, socio-economic characteristics of the population, location of important natural geographical divides, geographical consistency, etc. These are criteria that are to some extent already incorporated into the basic criteria, as they form the basis for regional administrative divisions of the state (see the sixth criterion in Table 1). With their help, we managed to create similarly sized and geographically more consistent constituencies.

When it came to automated districting of constituencies, given the time constraints, unavailability of relevant data and the fact that some criteria are very difficult to quantify and define, we did not take into consideration additional criteria. It is therefore not surprising that the proposed solutions conformed to a lesser degree to the principle of geographical consistency.

Another problem concerned the determination of weighting or ranking of selected criteria. Some criteria are mutually incompatible. Most problematic was harmonizing the requirement that constituencies be comparable in size (have the same number of voters) and be geographically consistent. This problem was solved "manually" by looking for solutions within the previously determined size limits, which preserved the integrity of spatial units (municipalities, settlements, town wards, and local communities). In practice, this meant that the geographical consistency (integrity of spatial units) was subject to given size constraints. Size restrictions were violated only in cases where strict adherence to them grossly violated the principle of geographical consistency for a large number of constituencies. In such cases, solutions deviating from the size limits were proposed. This underscores that during "manually" districting constituencies, the hierarchy of criteria was adapted to the specific situation, and in exceptional cases, minor deviations from the set criteria were permitted.

When employing automated districting of constituencies, such flexibility is not possible. The computer algorithm used is based on fixed rules and a clearly defined hierarchy of criteria. Having constituencies with approximately the same number of voters was defined as the most important criterion. In practice, it turned out that rigidly striving for the most comparable constituencies in terms of population size often leads to geographically consistent areas being broken up and the formation of geographically inconsistent constituencies.

Table 1. Key criteria used to develop proposals for a new system of constituencies in Slovenia (Rogelj et al., 2019a, 2019b)

1. size of constituencies (in terms of population) is determined based on the number of voters not on the number of inhabitants;

2. deviation in size of constituencies is determined in relation to the average size of a constituency at the national level (total number of voters divided by total number of seats (88)).

a) in the first proposal, the maximum tolerance was $+/-15 \%$.

b) in the second proposal, the maximum tolerance was $+/-25 \%$, exceptionally up to $+/-30 \%$.

c) in the third proposal, the maximum tolerance was $+/-25 \%$, exceptionally up to $+/-45 \%$.

3. municipalities and settlements serve as the foundational unit for districting constituencies; where possible, division of municipalities and settlements is avoided;

4. in the case of division of municipalities, the boundaries of settlements are taken into account;

5. only those settlements that are larger than the maximum permitted size for a constituency shall be divided; in the case of division of settlements, the boundaries of local, district or village communities are taken into account; exceptionally, census tracts are used for the districting of constituencies;

6. when merging spatial units, the boundaries of regional administrative divisions of the state are taken into account (boundaries of administrative units, statistical region, etc.);

7. the objective is to determine the best comprehensive solutions at the electoral district level. 
Based on the test cases, it is difficult to predict what solutions would be reached if more time, resources, and relevant data were available. We would probably get better solutions, but it is unlikely that these would be comparable or even superior to those prepared by the working group. The extraordinary com- plexity of the task, the experience gained through the work of the working group and examples from abroad show that districting of constituencies requires a certain degree of flexibility, which is difficult to incorporate into computer algorithms.

\section{Conclusions}

How useful are geoinformation tools in districting and redistricting of electoral districts? Based on our experience, we can say that they have become an indispensable part of the process. With their help, we can simplify and speed up the whole process and greatly reduce the possibility of various errors.

That said, modern geoinformation tools, despite the many possibilities they offer, are not omnipotent. Their usefulness is often limited by various external factors. The first major limitation is input data. The preparation of appropriate electoral district plans is possible only if relevant data are available. Without this, even the most state-of-the-art and sophisticated tools are completely useless.

The second limitation is related to rules and criteria. Geoinformation tools can be best used when the rules and criteria are clearly defined. Ambiguity in the rules and criteria has a negative effect on the transparency of the entire process, as it prevents an objective and impartial assessment of individual proposals. In our case, most problems were caused by the unclear definitions of two key criteria (equally populous and geographical consistent) used in districting. This fact was often used to criticize solutions that did not suit the interests of certain groups and individuals.

The third and, in our opinion, most important limitation is the willingness of stakeholders to take advantage of the opportunities offered by modern geoinformation tools. Political parties, the most prominent actors directing and supervising the process of redistricting in Slovenia, showed very little interest in exploiting the potential of geoinformation tools. This is partly due to a lack of familiarity with the technology, and partly to fear of losing control of the process. Geoinformation tools enable stakeholders and individuals to be actively involved in verifying proposals and finding new solutions. However, this is not to the liking of political parties, as they would lose their primacy over the process.

Even though the plans prepared by our group in all probability will not be included in amendments to the law, the experience and knowledge we gained will be useful in the preparation of similar plans in Slovenia and other countries.

\section{References}

ACE Project (2020). The ACE Electoral Knowledge Network. URL: https://aceproject.org/(14.7.2020).

Altman, M. (1998). Districting Principles and Democratic Representation. California Institute of Technology.

Altman, M. (1997). The computational complexity of automated redistricting: Is automation the answer? Rutgers computer \& technology law journal, 23(1), 81-142.

Altman, M., Macdonald, K., \& McDonald, M.P. (2005). From crayons to computers: The evolution of computer use in redistricting. Social Science Computer Review, 23(3), 334-346. DOI: $10.1177 / 0894439305275855$.

Altman, M., \& McDonald, M.P. (2019). The Public Mapping Project. Ithaca and London: Cornell University Press. DOI: 10.1353/book.62760.
Browdy, M.H. (1990). Computer Models and PostBandemer Redistricting. The Yale Law Journal, 99(6), 1379. DOI: 10.2307/796740.

Crampton, J.W. (2013). Commentary: Political applications of the geoweb: Citizen redistricting. Environment and Planning A, 45(1), 70-76. DOI: 10.1068/a44486.

Eagles, M., Katz, R.S., \& Mark, D. (2000). Controversies in political redistricting: GIS, geography, and society: editorial. Political Geography, 19, 135-139.

Eagles, M., Katz, R.S., \& Mark, D. (1999). GIS and Redistricting. Social Science Computer Review, 17, (1), 5-9. DOI: 10.1177/089443939901700101.

Gallagher, M., Mitchell, P. (Eds.) (2005). The Politics of Electoral Systems. Oxford: Oxford University Press. DOI: 10.1093/0199257566.003.0023.

Grad, F. (2004). Volitve in volilni sistem. Ljubljana: Uradni list Republike Slovenije. 
Gudgin, G., \& Taylor, P. (1979). Seats, votes, and the spatial organisation of elections. London: Pion.

Hess, S.W., Weaver, J.B., Siegfeldt, H.J., Whelan, J.N., \& Zitlau, P.A. (1965). Nonpartisan Political Redistricting by Computer. Operations Research, 13(6), 998-1006. DOI: 10.1287/opre.13.6.998.

Jelen, A., Bojc, D., \& Veršič, A. (2019). Proposal of new electoral districts and constituencies. Online ArcGIS application for political parties. Internal application with limited access. GDi d.o.o., Ljubljana.

Krašovec, A. (2007). Volilne študije. Ljubljana: Fakulteta za družbene vede.

Krevs, M., Veršič, A., \& Rogelj, B. (2020). Geoinformacijska podpora preoblikovanju območij volilnih enot in volilnih okrajev. In Ciglič, R., Geršič, M., Perko, D., \& Zorn, M. (Eds.). GIS-i v Sloveniji - Modeliranje pokrajine. Ljubljana: ZRC SAZU, pp. 133-147. DOI: https://doi.org/10.3986/9789610504696 10.

Morrill, R.L. (1981). Political Redistricting and Geographic Theory. Washington D.C.: Association of American Geographers.

Nagel, S.S. (1965). Simplified Bipartisan Computer Redistricting. Stanford Law Review, 17, (5), 863. DOI: $10.2307 / 1226994$.

Number of voters by house numbers for the territory of Slovenia (situation April 2019). Central Population Register. Ministry of the Interior (MNZ). Ljubljana.
Register of spatial units (situation April 2019). Surveying and Mapping Authority of the Republic of Slovenia (GURS). Ljubljana.

Rogelj, B., Krevs, M., Veršič, A., \& Prešern, M. (2019a). Predlog sprememb območij volilnih enot in volilnih okrajev (Poročilo Medresorske delovne skupine za pripravo sprememb in dopolnitev ZVDZ). Ljubljana.

Rogelj, B., Krevs, M., Veršič, A., \& Prešern, M. (2019b). Dopolnjen predlog sprememb območij volilnih enot in volilnih okrajev (Poročilo Medresorske delovne skupine za pripravo sprememb in dopolnitev ZVDZ). Ljubljana.

Veršič, A., \& Jelen, A. (2019). User's manual for online application "Proposal of new electoral districts and constituencies". Internal material with limited access. Ministry of Public Administration of the Republic of Slovenia. Ljubljana.

Vickrey, W. (1961). On the Prevention of Gerrymandering. Political Science Quarterly, 76(1), 105-110.

Weaver, J.B., \& Hess, S.W. (1963). A Procedure for Nonpartisan Districting: Development of Computer Techniques. The Yale Law Journal, 73(2), 288. DOI: $10.2307 / 794769$.

Webster, G.R. (2004). Representation, geographic districting, and social justice. Journal of Geography, 103(3), 111-126. DOI: 10.1080/00221340408978586 